\title{
Saberes sobre a malária: um estudo qualitativo baseado no Distrito do Lago, Província de Niassa (Moçambique - África)
}

\author{
Agostinho Ricardo Viana Carlos e Lima ${ }^{a^{*}}$, Fernando Mitano $^{\mathrm{b}}$ \\ aUniversidade Rovuma, Faculdade de Letras e Ciências Sociais, Niassa, Moçambique

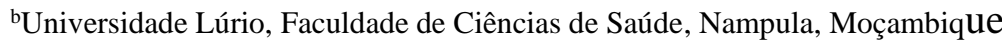

Histórico do Artigo:
Recebido em:
31/07/2020
Aceito em:
28/10/2020

Palavras-chave: Malária; prevenção; controle; saberes

Keywords:

Malaria; prevention; control; knowledge

\begin{abstract}
RESUMO
Procurou-se compreender o modo como a população do Distrito do Lago (Província de Niassa, Moçambique) percebe, previne e trata a malária. Trata-se de um estudo de cunho qualitativo, centrado na abordagem de modelos explicativos da doença, que contou com a participação de membros de agregados familiares, profissionais de saúde e médicos tradicionais. A coleta de dados aconteceu por meio de entrevistas, orientadas por um roteiro semiestruturado, realizadas nos meses de Setembro e Novembro de 2019 em 8 povoados do Distrito do Lago. Os resultados revelaram um entendimento de que a malária é uma doença causada pela picada de mosquito, perigosa e que mata quando não evitada (pelo uso da rede mosquiteira e a limpeza do pátio) e tratada através do Coartem ${ }^{\circledR}$ (arteméter + lumefantrina). Não obstante, a adesão às medidas convencionais prevenção e tratamento é determinada por factores socioeconómicos e estruturais, $o$ que faz com que a população recorra a outras alternativas de prevenção e de tratamento ou de obtenção do Coartem $^{\circledast}$. Com isso, pode-se dizer que a noção, a prevenção e o tratamento da malária pela maioria dos participantes assentam-se na perspectiva biomédica, ao passo que o modelo popular de prevenção e tratamento configura-se como alternativa ou complemento, sobretudo para as pessoas mais necessitadas.
\end{abstract}

Knowledges about malaria: a qualitative study based in Lago District, Niassa Province

(Mozambique - Africa)

\section{ABSTRACT}

We sought to understand how the population of Lago District perceives, prevents and treats malaria. It is a qualitative study centered on the explanatory models approach of the disease, in which members of households, health professionals and traditional doctors participated. Data collection was carried out through interviews, guided by a semi-structured script, carried out in September and November 2019 in 8 villages in Lago District (Niassa Province, Mozambique). The results revealed an understanding that malaria is a disease caused by mosquito bites, which is dangerous and kills when not prevented (by using mosquito nets and cleaning the patio) and treated through Coartem ${ }^{\circledast}$ (arteméter + lumefantrina). Nevertheless, adherence to conventional prevention and treatment measures is determined by socioeconomic and structural factors, which means that the population uses other alternatives for prevention and treatment or obtaining Coartem ${ }^{\circledR}$. With this, it can be said that the notion, prevention and treatment of malaria by most participants are based on the biomedical perspective, while the popular model of prevention and treatment is configured as an alternative or complement, especially for most needy patients.

\section{Introdução}

A malária ou paludismo é uma parasitose provocada pelo protozoário intracelular Plasmodium (P.), e é transmitida ao homem pela picada do mosquito Anopheles (1). Existem quatro (4) espécies de Plasmodium que infectam o homem, a saber: $P$. vivax (o mais frequente), $P$. falciparum (o mais virulento), $P$. ovale e $P$. malariae (1). Não obstante, o Plasmodium falciparum configura-se como sendo o mais predominante nos países da áfrica subsaariana, sobretudo em Moçambique onde é assolado por inúmeras

\footnotetext{
*Autor correspondente: alima@ unirovuma.ac.mz (Lima A.R.V.C.)
} 
doenças endémicas evitáveis, como é o caso da malária, que dia após dia tendem a minar o seu desenvolvimento. Essa doença representa a principal causa de internamento hospitalar e de mortalidade, sobretudo de crianças menores de 5 anos e mulheres grávidas, e, com efeito, constitui um dos fatores que degenera impiedosamente a economia familiar e nacional, na medida em que acarreta os custos com os cuidados de saúde, condenando as populações e o país à pobreza e ao sofrimento.

Em Moçambique a malária é responsável por $60 \%$ de todas as admissões pediátricas, por $40 \%$ do total de consultas e ainda por $30 \%$ de todas as mortes registadas nos hospitais (2). Com vista a reverter esse cenário, o governo moçambicano, por intermédio do Programa Nacional de Combate à Malária (PCNM) e de parceiros, tem levado a cabo cções centradas no (i) controle do vector (através da distribuição de redes mosquiteiras e pulverização intradomiciliária), (ii) manejo adequado de casos e, por fim, (iii) campanhas de educação para a saúde.

Com efeito, o país tem registado progressos na área de prevenção e manejo de casos de malária na população geral (3). A título ilustrativo, os dados obtidos nos Serviços Distritais de Saúde, Mulher e Ação Social do Lago revelaram uma redução dos casos de malária de 45,2\% em 2016 para 40.7\% em 2017. Recentemente, os dados do Inquérito Nacional sobre Indicadores de Malária (IIM) mostram que a percentagem de agregados familiares com pelo menos uma rede mosquiteira tratada com insecticida de longa duração para cada duas pessoas aumentou de 37,9\% em 2015 para 51,0\% em 2018 (3). Todavia, apesar desses avanços, os programas de controle da malária têm ainda enfrentado obstáculos relativos à mudança de comportamento por parte de certos indivíduos, o que concorre para que não se alcancem os objetivos plasmados. Por exemplo, no distrito do Lago, é visível o uso da rede mosquiteira em atividades voltadas, sobretudo, à pesca e à agricultura, num contexto em que a rede mosquiteira e o manejo de casos constituem as principais, se não as únicas, medidas de prevenção e de controle da malária disseminadas e providas pelas entidades da saúde.

No sentido de reverter esse cenário, alguns autores $(4,5)$ sugerem que as intervenções contra a malária sejam alicerçadas em evidências com base nos saberes e práticas locais ou, ainda, reflitam o conhecimento sistemático das percepções. Para tal, é necessário que haja um maior investimento e promoção de pesquisas em ciências sociais, em distintas regiões do país, para avaliar programas e serviços e documentar realidades ignoradas, particularmente as que se referem às representações, práticas e discursos (6). Essas representações e práticas espelham, no entender de Geertz (7), formas específicas de ver o mundo.

No campo da saúde, Kleinman, citado por Rabelo, Alves e Souza (8) categorizou os saberes e práticas terapêuticas em três subsistemas, a saber: profissional, folk e popular. Assim sendo, o subsistema profissional é constituído pela medicina científica (ocidental), pelas profissões paramédicas reconhecidas ou pelos sistemas médicos tradicionais profissionalizados (chinês, ayurvédico, unãni etc.). O setor folk é composto pelos especialistas "não oficiais" da cura (curandeiros, rezadores, espiritualistas e outros). O popular, por sua vez, compreende o campo leigo, não especializado da sociedade (automedicação, conselho de amigo, vizinho, assistência mútua etc.). Partindo dessa perspectiva, o estudo objetivou compreender o modo como a população do Distrito do Lago percebe, previne e trata a malária. Ao indagarmo-nos sobre esses elementos, procuramos captar as motivações respeitantes à escolha do provedor, às medidas preventivas utilizadas e ao tratamento (4), ou simplesmente, as alternativas terapêuticas. 


\section{Materiais e método}

Trata-se de um estudo do tipo qualitativo, realizado nos povoados de Mandambuzi, Ngoo, Nkologue, Ntumba, Ngofi, Messumba, Metangula e Cóbuè do Distrito do Lago, província de Niassa, conforme ilustra a Figura (1) abaixo.

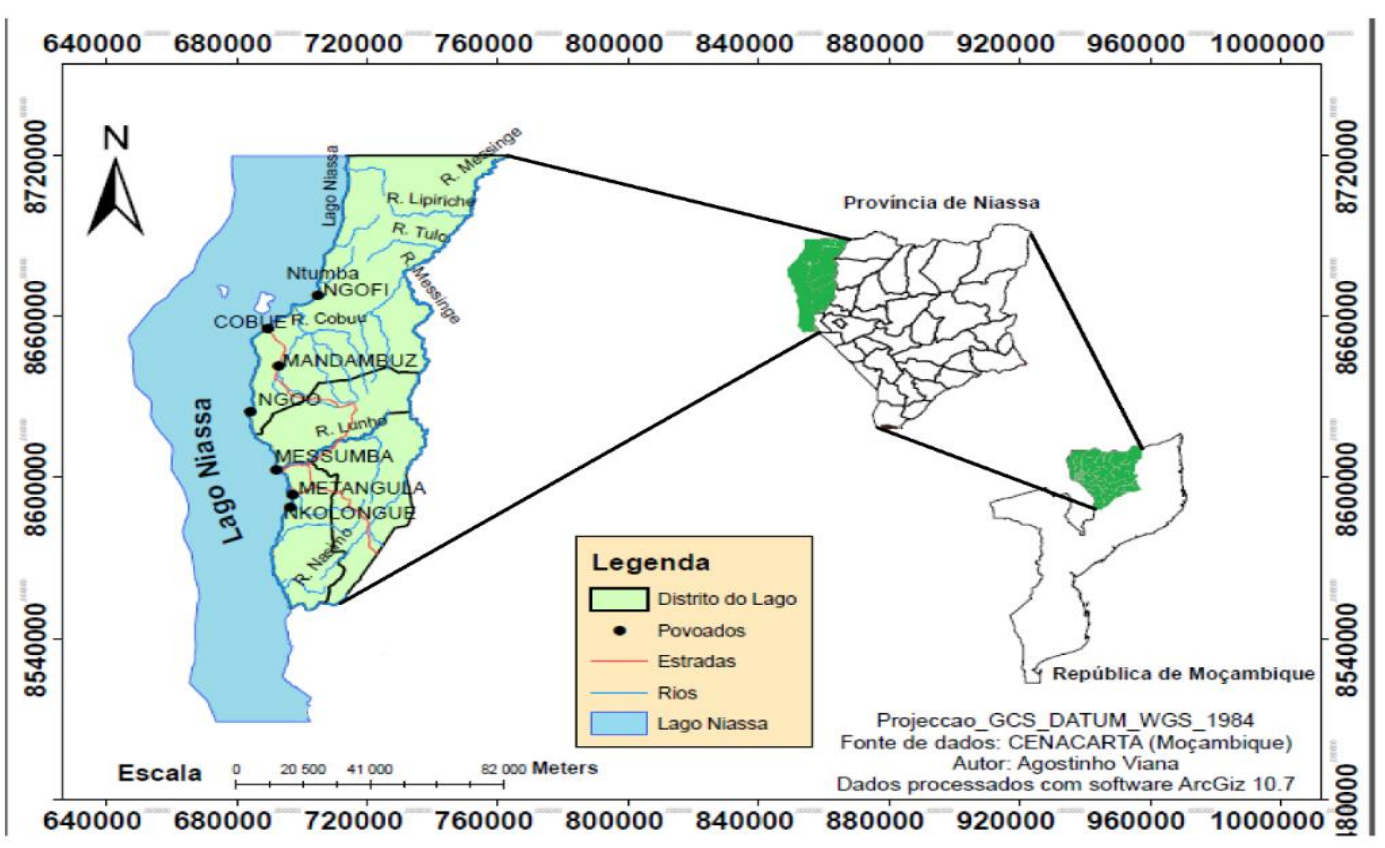

Figura 1 - Distribuição geográfica dos povoados do Distrito do Lago

A coleta de dados decorreu nos meses de Setembro e Novembro de 2019, através da entrevista semiestruturada e da observação direta ou simples. No entender de Gerhardt e Silveira (9), a entrevista semiestruturada caracteriza-se por ser aquela em que o pesquisador organiza um conjunto de questões (roteiro) sobre o tema que está sendo estudado, mas permite, e às vezes até incentiva, que o entrevistado fale livremente sobre assuntos que vão surgindo como desdobramentos do tema principal.

A entrevista seguiu um roteiro semiestruturado e foi fulcral na captação dos elementos discursivos usados pelos participantes para exprimirem as suas percepções sobre a malária. Ao passo que a observação direta permitiu captar certas práticas, sobretudo àquelas voltadas ao uso indevido da rede mosquiteira, e, com isso, confrontá-las com os depoimentos dos participantes, pois segundo orientam Gerhardt e Silveira (9), na observação directa ou simples o pesquisador permanece abstraído da situação estudada, apenas observa de maneira espontânea como os fatos ocorrem e controla os dados obtidos.

As entrevistas tiveram lugar nas residências dos participantes e nas unidades sanitárias, em língua portuguesa e nyanja (língua local de origem bantu) e com uma duração média de 30 a 45 minutos. Por intermédio de um tradutor local foi possível interagir com os informantes que não falavam ou tinham alguma limitação na língua portuguesa. De forma a salvaguardá-los, os depoimentos foram registados num bloco de notas e alguns, com o consentimento dos entrevistados, gravados e transcritos. Posteriormente, as entrevistas foram analisadas manualmente, segundo a natureza dos conteúdos.

O estudo contou com a participação de 40 membros de agregados familiares, 8 técnicos de Unidades Sanitárias e 2 médicos tradicionais. Os participantes foram 
selecionados por conveniência, obedecendo os seguintes critérios de inclusão: ter idade igual ou superior a 18 anos, residir numa das povoações do Distrito de Lago há mais de 2 anos e estar disponível para participar no estudo voluntariamente.

A incorporação dos técnicos de saúde e médicos tradicionais na pesquisa visou expandir o nosso entendimento sobre os modelos explicativos predominantes da malária e identificar a alternativa terapêutica com maior adesão no distrito.

A interação com os participantes era antecedida por uma apresentação do pesquisador e dos objetivos do estudo, seguido da leitura do termo de informação e da assinatura do termo de consentimento livre (em obediência às orientações plasmadas na Declaração de Helsinque). Com vista a garantir a privacidade dos entrevistados, os relatos foram codificados da seguinte maneira: Membros de Agregado Familiar (MAF), Técnico da Unidade Sanitária (TUS) e Médico Tradicional (MT).

Importa aclarar que, por desconfiança e medo, nem todos com os quais interagimos se predispuseram a participar da pesquisa, sobretudo quando eram solicitados a assinar o termo de consentimento livre. O estudo teve a aprovação do Comité Institucional de Bioética da Universidade Lúrio, com referência 192/Junho/CIBSUL/19.

\section{Resultados}

\section{Noção sobre a doença}

Quando questionados sobre o que era a malária, foi possível captar dos entrevistados a noção da malária como doença causada pela picada de mosquito e como doença perigosa e que mata.

"Malária é uma doença causa a pela picada de mosquito [...]" (MAF1, residente no povoado de Ngofi).

"A malária é uma doença perigosa e que mata. Muitas pessoas morrem aqui na comunidade por causa dessa doença [..]” (MAF2, residente no povoado de Mandambuzi).

\section{Manifestações da malária}

Com relação aos sintomas da malária, os participantes apontaram as "dores de cabeça", o "frio" e a "perda de apetite", conforme é demostrado nas narrativas abaixo:

\footnotetext{
"Quando a pessoa tem malária começa a ter dores de cabeça e a sentir frio" (MAF3, residente no povoado de Metangula).

"Malária faz você sentir muito frio, não ter vontade de comer e doe a cabeça. Mesmo quando está quente" (MAF4, residente no povoado de Messumba).
}

Como se pode ver, ao invocarem esses sintomas referenciavam-se apenas a malária não complicada ou não grave, caracterizada pela ocorrência de crises febris ou mal-estar geral, calafrios seguidos por febres, dores musculares e articulares generalizadas e manifestações digestivas, tais como vómitos e dor abdominal. Todavia, ao explorarmos um pouco mais os seus saberes apercebemo-nos que o termo missala, que na língua local Nyanja significa maluquice, era empregue por alguns para diferenciar a malária não complicada da complicada, em referência ao estado de confusão e delírio.

"A malária cerebral, para nós nhanja falamos missala que é maluquice, pessoas começam a falar coisas que não se percebe bem 
né” (MAF5, residente no povoado de Ngofi).

Ainda em conversa com os participantes, alguns apontaram que o estado de maluquice está associado aos efeitos do Coartem ${ }^{\circledR}$ e a subida do "bicho" ao cérebro, como se pode observar nos depoimentos a seguir:

"Há pessoas que não aguentam com aqueles comprimidos [Coartem ${ }^{\circledR}$ ], ficam baralhadas. Já ai não batem bem” (MAF6, residente no povoado de $\mathrm{Ngoo}$ ).

"Daquilo que eu sei, aquele bicho quando sobe para o cérebro as pessoas ficam malucas, falam coisas sem sentido" (MAF7, residente no povoado de Cóbuè).

Medidas de prevenção da malária

Quando questionados sobre as medidas de prevenção da malária os participantes invocaram, na sua maioria, a combinação de duas (2) estratégias: o "uso de redes mosquiteiras" e a "limpeza do pátio", como ilustram os trechos que se sequem:

"Para evitar a malária deve-se usar a rede mosquiteira e não deixar água suja e lixo no quintal" (MAF5, residente no povoado de Ngofi).

"A melhor forma de prevenir-se da doença é através do uso de rede mosquiteira e a limpeza do pátio" (MAF8, residente no povoado de Nkolongue).

No entanto, percebeu-se que algumas famílias não possuíam a rede mosquiteira porque, segundo estas, encontravam-se gastas ou haviam sido roubadas enquanto secavam após a lavagem. Em conversa com uma das participantes, percebeu-se que o uso da rede mosquiteira só foi possível depois do filho ter adoecido por malária. Segundo seu relato, ela não usava a rede mosquiteira porque quando assim o fazia ficava com uma sensação de sufoco por falta de ar. Esse discurso revela que a participante passou a usar a rede mosquiteira por temer que o filho voltasse a contrair a doença.

\footnotetext{
"Eu dantes não usava rede mosquiteira porque sentia que me sufocava, perdia o ar. Desde que J [código nosso] ficou doente e mal por causa de malária passei a usar rede mosquiteira" (MAF9, residente no povoado de Metangula).
}

Contudo, no entender de alguns entrevistados, a malária configura-se como um problema bastante antigo nessas comunidades, e que a adoção das medidas de prevenção resultam das ações ou campanhas de educação contra a doença, como ilustra a narrativa abaixo:

\begin{abstract}
"Malária é uma doença que nos preocupa bastante e não é de hoje. $O$ pessoal da saúde procura sempre sensibilizar as comunidades para usar a rede para se prevenir da malária. Alguns meses atrás esses da saúde mandaram e eu acompanhei para queimar aquelas redes [mosquiteiras usadas para secar o peixe] que estão no lago, porque as pessoas costumam a reclamar que não têm rede enquanto lá no lago está cheio" (MT1, residente no povoado de Metangula).
\end{abstract}

Porém, durante o estudo, observou-se e foi consubstanciado por alguns participantes 
que as redes mosquiteiras são usadas em atividades relacionadas com a pesca e a agricultura, como forma, segundo estes, de reaproveitar as redes gastas ou evitar a invasão de animais, como mostram os trechos abaixo:

\begin{abstract}
"As pessoas usam a rede para vedar as machambas [campos de cultivo] e amarar quintais porque elas não têm dinheiro para pagar palha [cordas] de pneu ou redes. Um rolo custa 50 meticais e estas redes são fortes" (MAF10, residente em Ngoo).

"Estas redes são gastas. Desde que recebemos em 2013 nunca mais. Ao invés de deitar, procuramos reaproveitar" (MAF11, residente no povoado de Ntumba).
\end{abstract}

Em conversa com um dos profissionais de saúde, soube-se também que certas mulheres grávidas ao receberem as redes mosquiteiras oferecem aos esposos ou acabam por vender.

\begin{abstract}
"Para além das pessoas terem recebido as redes nas campanhas passadas, as mulheres grávidas têm recebido redes mas estas oferecem aos seus maridos para secar peixe ou vendem aos pescadores" (TUS1).
\end{abstract}

No entanto, para alguns participantes a prevenção contra a malária estende-se, para além do uso da rede mosquiteira, a outras medidas locais, como: (i) a defumagem por meio da queima de capim, borracha e espirais de fumo (coils), (ii) o humedecimento das paredes, (iii) o uso de redes mosquiteiras como telas de janelas e, por último, (iv) a injeção da bizantinice.

"[...] quando você põe baygon ou queima serpentina o mosquito fica paulado, perde força. Uns morrem ai [...]” (MAF12, residente no povoado de Metangula).

"O pessoal não tem dinheiro para pagar udi [serpentina], por isso queimamos capim ou borracha. Aquele fumo faz com que os insectos como mosquito assim não respirem por falta de ar. Experimente você ficar num sítio com fumo, perde ar. Tem pessoas que já morreram por causa do fumo do fugão, e com o mosquito acontece o mesmo" (MAF13, residente no povoado de Mandambuzi).

"Algumas pessoas procuram molhar as paredes das casas porque acreditam que quando faz frio há poucos mosquitos" (MAF14, residente no povoado de Messumba).

"Usamos a rede mosquiteira para evitar a entrada de mosquitos $e$ outros bichos na casa. Não basta usar a rede mosquiteira [...] enquanto na sala e outros espaços está cheio de mosquito" (MAFl, residente no povoado de Ngofi).

"Quanto apanhas a injecção da bezentinica ficas todo ano bem, sem nenhuma febre e mal-estar" (MAF15, residente no povoado de Metangula).

\title{
Tratamento da malária
}

Ao serem questionados sobre onde buscavam o tratamento da malária, os participantes foram unanimes ao afirmar que recorrem ao hospital e isso ocorre após o prédiagnóstico dos sintomas da doença por eles feitos, como ilustram os depoimentos abaixo: 
"Para malária, penso que todos aqui na comunidade sabem que a melhor forma de tratar é indo ao hospital, porque lá tens aqueles testes rápidos que indicam se tens malária ou não. Quando tens, o técnico dá te coartem e paracetamol para tomar" (MAF12, residente no povoado de Metangula).

"Quando sinto assim frio, cabeça a dor, vou logo ao hospital. (...) Por vezes nem, posso ficar alguns dias só para ver se esses sintomas vão passar e quando não, epa, vou ao hospital" (MAF16, residente no povoado de Mandambuze).

No entanto, em conversa com os técnicos das US's percebemos que a adesão ao tratamento varia em função da disponibilidade de antimaláricos nas unidades sanitárias e da atividade agrícola.

"Quando recebemos Coartem ${ }^{\circledR}$ assistimos uma maior adesão dos pacientes. Fica cheio aqui" (TUS3).

"Quando é época de cultivo as famílias acabam por ir às machambas e o movimento tende a abrandar, até alguns pais levam as crianças para as consultas para obterem o Coartem $^{\circledR}$ para levar às machambas" (TUS4).

E, em consequência da ruptura de estoque dos fármacos, os técnicos de saúde revelaram que os pacientes tendem a recorrer aos mercados informais (feiras) ou ao vizinho Malawi, concretamente à ilha de Likoma. Outro dado relevante prende-se ao facto destes não cumprirem com a medicação por forma a reservar parte desta para uma eventual necessidade ou posterior venda.

\begin{abstract}
"As comunidades adquirem os fármacos nas feiras de comércio ou aqui na ilha de Likoma. Por acaso a ilha nos ajuda muito, porque é mais fácil e barato ir a Likoma do que a sede de Metangula" (TUS4).

"Por causa disso, as pessoas por vezes não cumprem com a mediação. Eles guardam uma parte para usarem em outra ocasião ou venderem quando ficamos sem Coartem ${ }^{\circledR, "}$ (TUS5).
\end{abstract}

Contudo, um dos técnicos das US's revelou também que os pacientes tendem a simular sintomas de malária na tentativa de obterem o Coartem ${ }^{\circledR}$. Ao passo que o outro afirmou que certos indivíduos dirigem-se às unidades sanitárias assim que sentem algum sintoma associado à malária e outros depois de terem administrado algum medicamento e que ainda que o Teste de Diagnóstico Rápido (TDR) dê negativo os pacientes veem o Coartem ${ }^{\circledR}$ como o único fármaco a ser administrado para a reposição da saúde ou eliminação dos sintomas.

"Quando temos fármacos, temos tido muita afluência de pacientes. Alguns até tentam fingir que estão doentes para obter o Coartem ${ }^{\circledR}$ ", (TUS5).

"Algumas pessoas vêm aqui enquanto já tomaram algum medicamento e outras vem logo que tem algum sintoma idêntico ao da malária. E mesmo o teste dando negativo, eles querem que sejam dados Coartem $^{\circledR ”}$ (TUS6).

Em conversa com os médicos tradicionais, percebeu-se também que algumas pessoas recorrem ao tratamento tradicional quando o teste de diagnóstico da malária é negativo 
mas as febres persistem.

\begin{abstract}
"Outros quando vão ao hospital e acusa negativo, veem aqui. Quando digo para ir ao hospital, eles até costumam a negar e mesmo assim eu digo para ir. Depois de confirmar-se que não é malária, é que eu costumo a dar o tratamento" (MT1, residente no povoado de Cóbuè).

"Malaria não vou mentir, dizer que aqui tem tratamento tradicional de malária, não. Febres têm, febres de espírito. Este costumo a tratar. Tem três tipos, tem febres de espírito mau, tem febres de malária, tem febres que acusa parece maluquice [que leva o paciente a agir de forma anormal]. Quando as pessoas vêm com esses sinais, antes de tratar eu costumo a mandar para o hospital. Quando faz análise e não acusa malária, é tradicional e eu costumo a tratar" (MT2, residente no povoado de Metangula).
\end{abstract}

Estes depoimentos revelam um entendimento de que o tratamento da malária é apenas hospitalar pelo facto de esta não originar de um desequilíbrio espiritual, conforme acontece com outras doenças febris. Nessa perspectiva, o TDR é que determina se a febre é espiritual ou simplesmente uma manifestação da malária, isto é, quando um paciente com febres é sujeito ao teste de malária e o resultado é negativo, significa que a febre é (ou tem uma causa) espiritual.

\title{
4. Discussão
}

De acordo com os depoimentos dos nossos entrevistados, identificou-se duas visões sobre a malária: a primeira baseada na etiologia (doença causada pela picada de mosquito) e a segunda nas consequências (doença perigosa e que mata). Diante dessas duas visões sobre a malária, a maioria dos entrevistados reconhece e assume a rede mosquiteira, a limpeza do quintal e o cuidado médico (sobretudo a base da administração do $\operatorname{Coartem}^{\circledR}$ ) como sendo as principais medidas de prevenção e tratamento da malária. Dois fatores contribuíram para o enriquecimento dos conhecimentos dos nossos entrevistados sobre a malária.

O primeiro prende-se às campanhas de educação contra a malária levadas a cabo pelas entidades de saúde e parceiros como, por exemplo, a que teve lugar, entre os anos de 2014 a 2017, nas províncias de Nampula e Niassa onde, segundo a Malaria Consortium (10), para além da distribuição de um conjunto de materiais didáticos com mensagens gerais sobre a prevenção da malária, mais de um milhão de agregados familiares beneficiou-se também de Rede Mosquiteira de Longa Duração Tratada com Inseticida (REMILD).

O segundo fator diz respeito à "experiência concreta" com a doença, "acumulada ou vivenciada" (11) pelos sujeitos da pesquisa que vêm revelar, a partir da noção da malária como uma doença "perigosa" e que "mata", sentimentos de perda, medo de adoecimento e da morte. É no quadro desses saberes e sentimentos, aliado às limitações das entidades de saúde em prover medidas complementares ao uso da rede mosquiteira (como, por exemplo, a pulverização intradomiciliária) que "a sociedade" vê-se "obrigada a procurar outros meios" (12) locais de prevenção, como: (i) a defumagem por meio da queima de capim, borracha e espirais de fumo (coils), (ii) o humedecimento das paredes e, por último, (iii) o uso de redes mosquiteiras como telas de janelas. No caso da primeira alternativa, um estudo similar realizado por Sequeira (4) no Distrito de Chókwè revelou que algumas famílias recorriam a vários comburentes, como o capim, as velas, as caixas, as cascas de ovos e os caroços de maçaroca para se prevenirem da malária. Com isso, nota-se que a adopção dessa medida é movida pela crença de que a 
fumaça age, à semelhança do inseticida, como uma tela "protetora que impede a infestação ou elimina os mosquitos" evitando "a picada nas pessoas" (13).

No entanto, Biran et al. (14) defendem haver evidências anedóticas de que o fumo é um repelente eficaz de insetos, pois certos estudos relataram que o fumo de uso doméstico impede os mosquitos de descansar ou hibernar em casas, não havendo alguma associação entre a fumaça e a redução no número de mosquitos Anopheles. Para esses autores (14), o problema com a fumaça do uso doméstico é que qualquer efeito repelente que possa ter suportaria o custo de aumentar os riscos de problemas respiratórios agudos e crônicos.

Quanto à segunda alternativa (humedecimento das paredes) resulta da ideia de que na época quente a propagação do mosquito é maior que na fria. $\mathrm{Na}$ verdade, esse entendimento é consubstanciado por Ogden et al. (15), ao afirmarem que a temperatura afeta a taxa de desenvolvimento de ovos dos mosquitos, larvas e pupas, com temperaturas mais quentes a acelerarem o ciclo de vida do mosquito bem como a rapidez com que os mosquitos adultos se multiplicam (16). Essa ideia é também secundada por Marinho et al. (17), ao referirem que as temperaturas de $10^{\circ} \mathrm{C}$ ou menos limitam o desenvolvimento larval e a sobrevivência do mosquito adulto, enquanto as temperaturas que variam de $22^{\circ} \mathrm{C}$ a $32^{\circ} \mathrm{C}$ constituem-se ideais para o desenvolvimento, longevidade e fecundidade dos mosquitos. Todavia, no nosso entender, o humedecimento das paredes pode gerar efeitos contrários aos desejados, ou seja, favorecer a atividade (reprodução e picada) do mosquito e, com isso, o aumento dos casos da doença.

Por fim, a adoção da terceira alternativa (uso de redes mosquiteiras como telas de janelas) surge no sentido de impedir a entrada do mosquito nas residências, visto que, segundo argumentam Bigoga et al. (18), a emergência de mosquitos adultos geralmente ocorre à tarde e a entrada nas habitações começa no crepúsculo e tem o seu pico entre as 22:00 e 02:00 horas. Após as 8:00 horas, pode ser observada pouca movimentação dos mosquitos para fora e dentro das casas mas ao anoitecer as fêmeas em jejum e grávidas que estavam abrigadas dentro da casa durante o dia saem para se alimentar e ovipor (17).

Contudo, apesar da adopção dessas medidas locais, depreendeu-se que o uso da rede mosquiteira por parte dos nossos entrevistados configura-se como a principal ferramenta "de intervenção primária contra os vetores da malária" (18). Ainda assim, ficamos com reservas de afirmar categoricamente que há uma "diminuição de má prática" através da "consciencialização das pessoas sobre o risco da malária, e eficácia comprovada das redes" (19). Isso porque as narrativas dos nossos entrevistados revelaram algumas limitações na adesão a essa medida e ao tratamento hospitalar derivadas do fraco poder económico das famílias e das fragilidades das entidades de saúde em fazer frente à demanda por antimalárico $\left(\mathrm{Coartem}^{\circledR}\right)$. Por exemplo, devido a necessidade que grande parte das famílias do Distrito do Lago tem em assegurar as suas fontes de subsistência, assiste-se, por um lado, "o deslocamento temporário" destas "e por vezes a fixação de uma nova residência próximo das áreas de cultivo" (20), fato que, no entender de Abdula (21), leva-as a abandonar o tratamento hospitalar e o atendimento sanitário diverso, e, por outro lado, assiste-se o uso da rede mosquiteira na secagem de peixe e proteção das áreas de cultivos e viveiros contra a invasão de animais. Isso dá-se, concordando com Chidassicua (11), não apenas pela necessidade da garantia da subsistência da família pelas condições precárias em que as pessoas vivem mas também pela resistência da rede, fazendo com que esta, para além de servir de meio de prevenção contra a malária, tenha outras utilidades e torne-se num bem substituto de rede metálica, tela de janelas e corda.

Essa situação, na análise de Mitano, Ventura e Palha (22), requer que o país aplique 
políticas de redistribuição de renda e de atenção à saúde em populações mais carentes, visto que a falta do desenvolvimento da saúde em Moçambique é caracterizada pela má qualidade de vida e pela falta de educação básica capaz de levar a população a reconhecer minimamente as medidas de prevenção de determinadas doenças e as formas de tratamento, apelando, dessa forma, para uma reflexão profunda e uma atitude de mudanças rápidas na área de educação e saúde, incluindo da agricultura.

Quanto às fragilidades das entidades de saúde em fazer face à demanda por antimalárico $\left(\right.$ Coartem $\left.^{\circledR}\right)$, as narrativas dos técnicos de saúde revelaram que, em dado período, certas unidades sanitárias têm registado ruptura de estoque de antimalárico $\left(\right.$ Coartem $\left.^{\circledR}\right)$. Esse facto, no entender de Abdula (23), deriva mais das falhas de gestão por parte dos que coordenam o sector e não da ruptura de estoque nos armazéns.

No entanto, Cavelane (24) denuncia que a ruptura de estoque de medicamentos em Niassa está, em alguns casos, relacionada com o desvio de medicamentos por parte do pessoal clínico e agentes de farmácia para posterior venda nas farmácias privadas, residências e mercados informais.

Como consequência, os depoimentos dos técnicos de saúde mostraram que o incumprimento da medicação (tratamento) e o recurso aos mercados informais e às unidades sanitárias do vizinho Malawi, concretamente na ilha de Likoma, surgem para os pacientes como alternativas de obtenção de Coartem ${ }^{\circledR}$ e de tratamento. Esse cenário, corroborando com os autores Reiners et al. (25), contribui não apenas no controle inadequado da doença mas também no aumento dos custos em saúde, impactando na vida das pessoas, famílias e ações do governo no sentido de combater e controlar a malária. Todavia, por tratar-se de um estudo de carácter qualitativo, os seus resultados não são passíveis de generalizações, visto que buscou-se captar apenas as percepções dos nossos entrevistados sobre a malária e as suas medidas de prevenção e tratamento.

Contudo, apesar dessas percepções e medidas não estenderem-se aos demais membros das comunidades do Distrito do Lago, o estudo reveste-se de tamanha importância por contribuir no entendimento das motivações relativas à escolha do provedor, às medidas preventivas e ao tratamento da malária, e também por servir de evidências para pesquisas científicas e elaboração de estratégias de prevenção e controle da malária.

\section{Considerações finais}

Pelos relatos descritos, compreendeu-se que a noção, a prevenção e o tratamento da malária pelos participantes assentam no modelo biomédico, sobretudo por estes verem o Coartem ${ }^{\circledR}$ como o principal mecanismo de cura da malária. Esse facto, induz-nos a assumir que a malária é vista como um distúrbio de ordem biológica e não espiritual. Todavia, a sua adesão é ainda determinada por fatores socioeconómicos (a pobreza) e estruturais (a precariedade dos serviços de saúde), que fazem com que o modelo popular de prevenção da malária surja como alternativa ou o complemento, para os mais carenciados.

Essa situação revela que, enquanto a qualidade de vida e dos serviços de saúde for débil ou incapaz de dar resposta às necessidades de saúde e de subsistência, a informação e o conhecimento sobre a malária não serão, por si só, suficientes para gerar mudança do comportamento da população. Daí que as intervenções de prevenção e controle da malária devem se fazer acompanhar pela melhoria das condições de vida das populações e do fortalecimento dos serviços de saúde, sobretudo a disponibilidade de fármacos (antimaláricos) nas unidades sanitárias, o incremento de medidas combinadas de controle de vetor e, por fim, o desencorajamento de práticas que tendem a obstruir os esforços empreendidos pelas entidades de saúde por meio de um Sistema de Vigilância 
Vittalle - Revista de Ciências da Saúde v. 32, n. 3 (2020) 107-118

Sanitária acurado.

\section{Agradecimentos}

Ao Fundo Nacional de Investigação (FNI) pelo financiamento concedido para a realização da pesquisa de campo.

\section{Conflito de interesse}

Os autores declaram a inexistência de conflitos de interesses na elaboração da pesquisa.

\section{Referências}

1. Secção de Infecciologia Pediátrica da Sociedade Portuguesa de Pediatria. Malária - Protocolo Diagnóstico e Terapêutico. Acta Pediatr Port 2006; 37(5): 205-9.

2. N'weti. Malária: O que separa o conhecimento do comportamento. $1^{\mathrm{a}}$ ed. Maputo: INLD; 2011.

3. Instituto Nacional de Saúde (INS) e International Finance Corporation (ICF). Inquérito Nacional sobre Indicadores de Malária em Moçambique 2018. Maputo: INS e ICF; 2019, 190p.

4. Sequeira AR. A Malária em Moçambique: Políticas, Provedores de Cuidados, Saberes e Práticas de Gestão da Doença. Lisboa: Centro de Estudos Internacionais do Instituto Universitário de Lisboa; 2017, 341p.

5. Crespo APA, Gurovitz E. A Pobreza como um fenómeno multidimensional. RAE- eletrônica 2002; 1(2): 02-12.

6. Loforte AM. Inequidades e Valores em Saúde Reprodutiva: Vulnerabilidade das Mulheres num Contexto de Feminização da SIDA. In: Medicus Mundi Catalunya (Org.). Mulher, sida e o acesso à saúde na África Subsahariana, sob a perspectiva das ciências sociais [Internet]. 2007 [Citado em 20 Fevereiro de 2020]. Disponível em www.medicusmundi.es/catalunya

7. Geertz C. O Saber Local: novos ensaios em antropologia interpretativa. $7^{\text {a }}$ ed. Rio de Janeiro: Vozes; 1997.

8. Rabelo MCM, Alves PCB, Souza IMA. Experiência de doença e narrativa. Rio de Janeiro: Editora FIOCRUZ; 1999, 264p.

9. Gerhardt TE; Silveira DT (Org.). Métodos de pesquisa. Porto Alegre: Editora da UFRGS; 2009, 120 p.

10. Malaria Consortium. A rede traz saúde: Uma auscultação qualitativa sobre as práticas de uso e cuidado de redes mosquiteiras em duas províncias do norte de Moçambique [Internet]. 2017 [Citado em 10 de Setembro de 2019]. Disponível em: http://www.malariaconsortium.org/projects/malariaprevention-and-control-project

11. Chidassicua JB. Práticas e saberes socioculturais sobre saúde, doença e morte de crianças de 0 a 5 anos de idade, na comunidade de Mopeia (Moçambique). Dissertação [Mestrado em Saúde Pública] Curso de Pós-Graduação em Saúde Pública, Universidade de São Paulo; 2011.

12. Mutiua C. O saber local em busca de soluções tradicionais para problemas modernos nas sociedades costeiras de Cabo Delgado [Internet]. [Citado em 25 de Fevereiro de 2020]. Disponível em: http://www.acervodigitalsuaili.com.br/portal/uploads/page/1E7B89ECAF.pdf

13. Santos CHF. Condições ambientais e transmissão de malária e dengue: um estudo das percepções dos moradores do entorno sul da Reserva Florestal Ducke - Manaus-AM. Dissertação (Mestrado em Ciências do Ambiente e Sustentabilidade na Amazônia) - Curso de Pós-graduação em Ciências do Ambiente e Sustentabilidade na Amazônia, Universidade Federal do Amazonas; 2009.

14. Biran A, Smith L, Lines J, Ensink J, Cameron M. Smoke and Malaria: Are Interventions to Reduce Exposure to Indoor Air Pollution Likely to Increase Exposure to Mosquitoes and Malaria? Trans R Soc Trop Med Hyg 2007; 101(11): 1065-71.

15. Ogden NH, Lindsay LR, Ludwig A, Morse AP, Zheng H, Zhu H. Weather-based forecasting of mosquito-borne disease outbreaks in Canada. Can Commun Dis Rep 2019; 45(5): 127-32.

16. Wegbreit J, Reisen WK. Relationships among weather, mosquito abundance, and encephalitis virus 
activity in california: Kern county 1990-98. Jornal of the American Mosquito Control Association 2000; 16 (1):22-27.

17. Marinho RA, Beserra EB, Bezerra-Gusmão MA, Porto VS, Olinda RA, Dos Santos CAC. Effects of temperature on the life cycle, expansion, and dispersion of Aedes aegypti (Diptera: Culicidae) in three cities in Paraiba, Brazil. Journal of Vector Ecology 2016; 41(1): 1-10.

18. Armando EJ. Avaliação de Novas Metodologias de Captura de Anopheles (Nyssorhynchus) darlingi Root, 1926 (Diptera: Culicidae) e Anopheles (Cellia) funestus Giles, 1900 (Diptera: Culicidae). 2014. 78f. Dissertação [Mestrado em Parasitologia] - Curso de Pós-Graduação em Parasitologia, Universidade Federal de Minas Gerais; 2014.

19. Malaria Consortium. Mobilizando as comunidades para a prevenção da malária em Moçambique [Internet]. 2017b [Citado em 10 de Setembro de 2019]. Disponível em: http://www.malariaconsortium.org/projects/malaria-prevention-and-control-project

20. Jossias, E. M. F. O primeiro a chegar é o dono da terra: pertença e posse da terra na região do Lago Niassa. 2016. 253f. Tese [Doutoramento em Antropologia] - Especialidade em Antropologia da Etnicidade e do Político, Universidade de Lisboa; 2016.

21. Abdula N. Aumento de nomadismo causa abandono nos tratamentos sanitários [TVM Online]. [Citado em 06 de Fevereiro de 2020]. Disponível em: https://noticias.tvm.co.mz/index.php/saude/item/1094-aumento-de-nomadismo-causa-abandono-nostratamentos-sanitarios

22. Mitano F, Ventura CAA, Palha PF. Saúde e desenvolvimento na África Subsaariana: uma reflexão com enfoque em Moçambique. Revista de Saúde Coletiva 2016; 26 (3):901-915.

23. Matine J. Falta de Medicamento nos Hospitais Públicos Associada a Falta de Responsabilização dos Gestores do Sistema Nacional de Saúde. $6^{\mathrm{a}}$ ed. Maputo: CIP, 2015. 36p.

24. Cavelane BH. Mais Vida. $1^{\text {a }}$ ed. Maputo: CIP; 2019.

25. Reiners AAO, Bruna BB, Azevedo RCS, Fontes CJF, Souza TG, Ferreira RG, Taísa GS. Estudos sobre adesão ao tratamento da malária. Enfermería Global 2013; (32): 304-319. 